\title{
Business and IS/IT Strategic Alignment Framework
}

\author{
Llanos Cuenca, Angel Ortiz, and Andres Boza \\ Research Centre on Production Management and Engineering, Universidad Politécnica de \\ Valencia, Camino de Vera, s/n 46022 Valencia, Spain \\ \{1lcuenca, aortiz, aboza\} @cigip.upv.es
}

\begin{abstract}
Incorporating information systems and information technology (IS/IT) in the organizations have considerable risks, and these risks are increased when a strategic plan for its incorporation is not done. The objective of this research is to contribute in the alignment between business and IS/IT strategies using concepts and techniques from engineering and enterprise architecture. To achieve this objective, this research proposes to define a modeling framework for business and IS/IT strategic alignment. The implementation of this proposal in a ceramic tile company has helped to validate its usefulness.
\end{abstract}

Keywords: Strategic alignment, framework, business, IS/IT, enterprise engineering.

\section{Introduction}

The current economic conditions and the high level of market uncertainty, forces the companies to be in a continuous adaptation to respond constant changes. Information systems and information technology (IS/IT) are crucial, bringing added value to business or even changing the way we carry them out. Enterprise architecture, considered as the foundation of enterprise systems engineering, has emerged as a 'tool' to help stakeholders to manage system engineering and changes. It is not only an IT issue, but first of all a strategic and organizational challenge [1]. Aligning IS/IT and business strategy is a key in maintaining business value [2], [3], [4], [5]. This alignment is not easy, neither in its conceptualization [6], [7], [8], nor in its accomplishment [7]. In fact, the lack of this alignment has been the reason for not achieve the improvement expected through their investments in IS/IT [9], [2], [10], [11].

The main purpose of this research is to improve the alignment between business and IS/IT strategies, making use of enterprise engineering. Modeling IS/IT by building blocks allows facilitating alignment with the business since the early phases of life cycle and incorporating the building blocks in enterprise architectures.

\section{Contribution to Technological Innovation}

Technological innovation can improve competitiveness of a company. This competitiveness improves when add value is included in all business process. IS/IT allows 
making better this value chain improving the enterprise processes or defining new processes changing the way companies do business. In this sense, it is important to define and to align business and IS/IT strategy. In this paper two disciplines are combined, IS/IT strategic planning and enterprise architecture.

\section{Related Work}

Enterprise Engineering (EE) allows understanding, defining, specifying, designing, analyzing, and implementing business processes for the entire life cycle, so that the enterprise can achieve its objectives [12], [13]. Enterprise Architecture (EA) is the discipline of designing enterprises guided with principles, frameworks, methodologies, requirements, tools, reference models and standards. EA is a set of descriptive representations that are relevant for describing an enterprise such that it can be produced to management's requirements and maintained over its period of useful life [14], [15]. The alignment is the degree of fit and integration among business strategy, IT strategy, business infrastructure, and IT infrastructure [2]. The works analyzed in this research include enterprise architecture (Zachman [14], TOGAF [16], EAP [17], DoD AF [18], CIMOSA [19], GERAM [20] e IE-GIP [21]), strategic alignment models (Henderson y Venkatraman [2], Luftman [22], Maes [23], Santana [24]) and works on both subjects [25], [26], [27], [28], [29], [30], [31], [32].

\subsection{Critical Analysis}

Enterprise architecture frameworks organize, manage and interrelates a wide variety of models used to structure and operate an enterprise by taking into account all possible views. A modeling view is a representation of a whole system from the perspective of a related set of concerns [33], [20]. All the analyzed Enterprise Architectures contain views in their frameworks, however, life cycle, building blocks, and how the building blocks fit together, is not defined by all of them. Life cycle is related to the life cycle of the entity being modeled. The life cycle of an enterprise model is the result of the model development process by which models are created, made operational and finally discarded [34]. A building block is a primitive component (with syntax and semantics) of a modeling language [12].

This analysis has allowed defining different views: Business, Resource, Organization, Information, Data, Application and Technological Views. The proposal maintains, in most cases, a definition according to the architectures analyzed. In case of differences between similar views of different architectures its redefinition has been necessary. Business View contains business process and business entity in a company; Resource View contains capabilities and resources; Organization View includes organization levels, authority and responsibility; Information View contains input and output process; Data View defines types and data sources needed to support the information view; Application View identifies the application needs and data presentation; Technological View determines the technology to use and defines how this 
technology should be used. The starting point for the analysis of the life cycle phases was CIMOSA, IE-GIP, EAP and TOGAF, because they are the most complete. CIMOSA and IE-GIP do not provide concepts related to information systems and technologies in earlier phases. Neither do they include aspects related to the conceptualization of IS/IT. Moreover, the business model of EAP does not include TO-BE process definition and does not establish an action plan. In this sense, IE-GIP is more complete. This action plan is partially covered in TOGAF but is mainly directed by business strategy.

Formal definition is less common in strategic alignment models, in this sense; they do not include building blocks nor life cycle phases. Hence, it is not possible its definition under the enterprise engineering approach, which is solved in this proposal.

\section{Business and IS/IT Strategic Alignment Framework}

The proposed business and IS/IT strategic alignment framework has been included in the CIMOSA [19] and IE-GIP [21] modeling framework, new life cycle phases and building blocks. Three new phases have been defined: Business and IS/IT conceptualization, Business Process and IS/IT definition and Business and IS/IT master plan. New building blocks are defined for these phases and integrated with the other building blocks [36] (Fig.1).

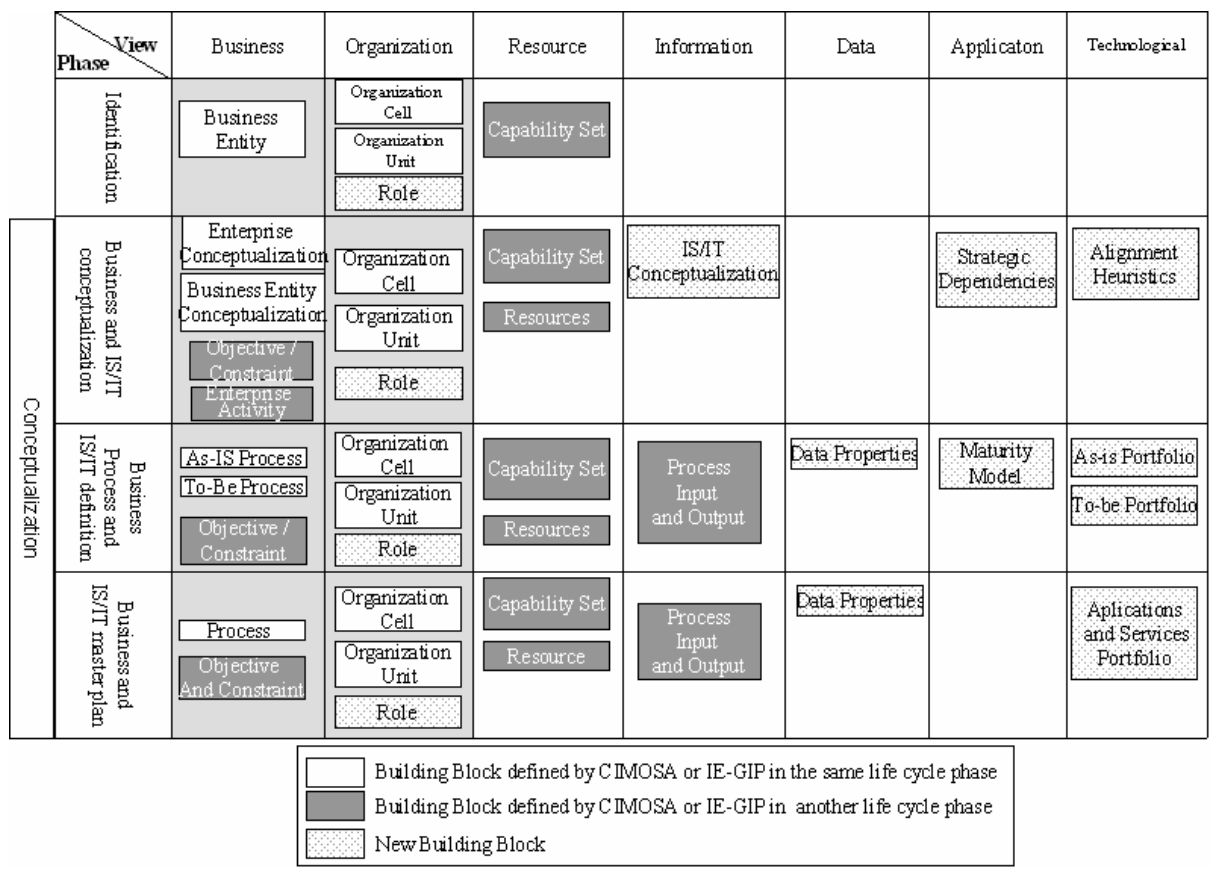

Fig. 1. Business and IS/IT strategic alignment framework 
The definition of the building blocks of CIMOSA and IE-GIP is detailed in [19] and [21]. The new building blocks are:

- Role: Represents the profile required to undertake a task. It can be assigned to an organizational unit, a business process or an enterprise activity building block. The roles will be used in the modeling phases where these building blocks will be used. The roles are assigned to the organization view.

- IS/IT Conceptualization: Indicates whether the IS/IT strategy and its alignment with the business has been completed. The constructor is used in the conceptualization phase and it is associated with the information view.

- Alignment heuristics: The purpose is to detect possible failures in the alignment. The constructor is used in the conceptualization phase and it is associated with the technological view.

- Strategic dependencies: It is based in I* framework [37]. The purpose is to detect dependencies between actors, roles, organization unit, organization cell or set of roles that depends on another role. The constructor is used in the conceptualization phase and it is associated with the application view.

- As-IS portfolio: The purpose of the as-is portfolio is to support the information associated with each application and its relationship with as-is business objectives. It is used in the business process and IS/IT definition phase. It is associated with the technological view.

- To-Be portfolio: The purpose of the to-be portfolio is to support the information associated with each application and its relationship with to-be business objectives. There must be at least a relationship with a business objective. It is used in the business process and IS/IT definition phase. It is associated with the technological view.

- Maturity Model: It is based on the maturity models of Luftman [22] and Santana [24] and allows you to define the maturity level of strategic alignment. It is used in the business process and IS/IT definition phase. It is associated with the application view. The alignment will be assessed using a rating scheme of five levels. Level 1: No Alignment, Level 2: Beginning Process, Level 3: Establishing Process, Level 4: Improved Process, Level 5: Complete Alignment.

- Data properties: It defines the properties for the inputs and outputs of process, identifying the type and source of data and storage, retrieval and data availability. It is used in the business process and IS/IT definition phase. It is associated with the data view.

- Application and services portfolio: The applications and services portfolio include those that have been identified in the to-be portfolio and those who remain in the as-is portfolio. It is used in the master plan phase and is associated with the application view.

\subsection{Building Block Templates and Relations}

Each building block is represented with a template [34], [35]. Figure 2 shows the maturity model building block. 
Type:

Narte:

Identification: |w|

Design Responsible: U- responsible for designing and maintaining this building block

Stakeholder: $\sqcup-$ o $\mathrm{C}$ - stakeholder of the business entity on which the maturity analys takesplace

Eusiness Entity: Warme or ID

Criterion: Criteria seleded

attribute: attributes of criteria analyzed

Level: [1 . . 5] Level assigned

Responsible: L- o C- responsible for asigning the attribute level

Review Date: The date that is discussed or revewed and the corresaonding attribute is assigned a level of rmaturity.

Final asigned level: Nil or level.

Awerage level of criteria tor sakeholder: value

Average level of criteria or the business entity value

Fig. 2. Maturity model template

In addition, to ensure the modeling framework integrity, the building blocks are related to each other. The following figure shows the relationship in the business and IS/IT conceptualization phase and the contents of some building blocks.

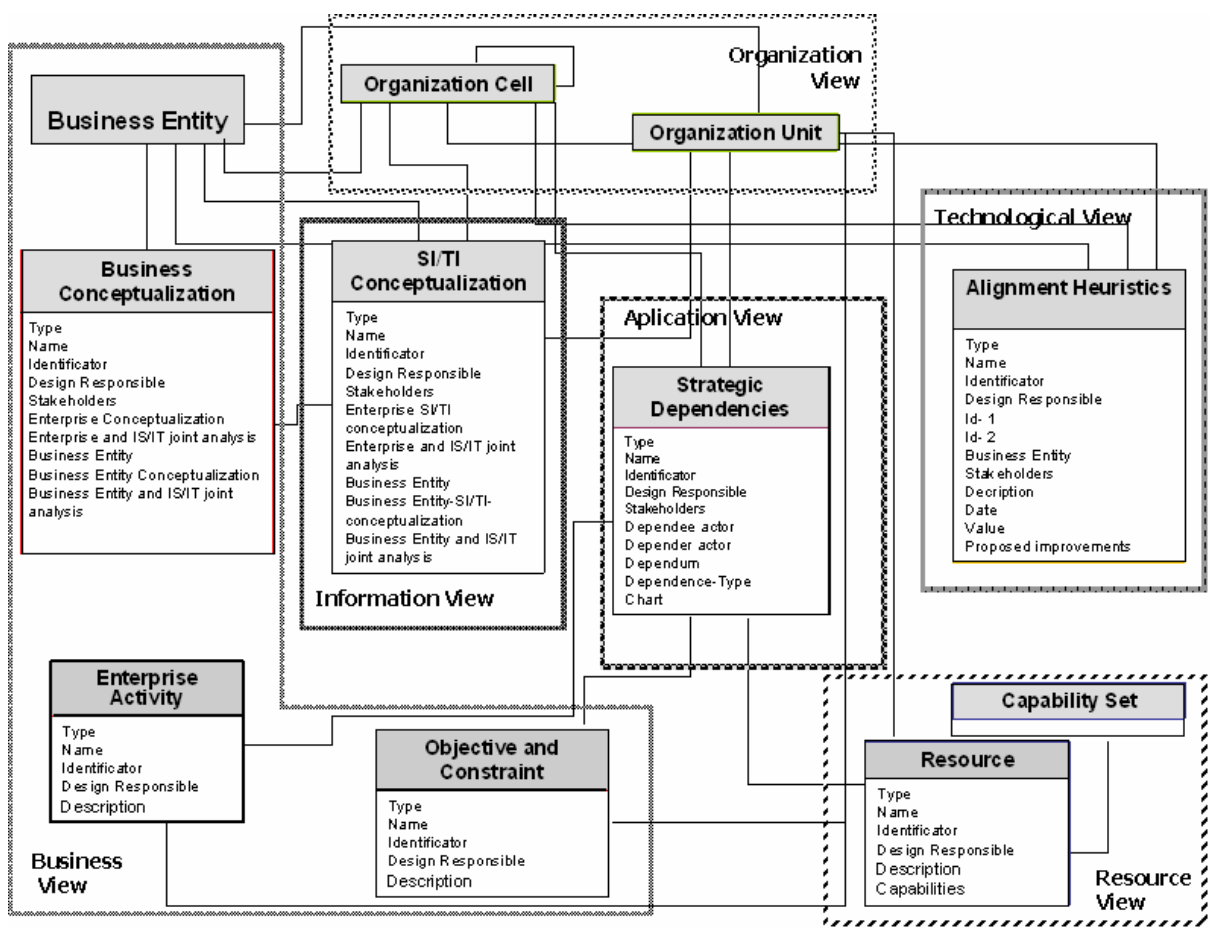

Fig. 3. Building blocks relations in business and IS/IT conceptualization phase 


\section{Case Study}

The proposed modeling framework has been applied in a ceramic tile company. It was necessary several interviews with the managers appointed by the company, and the outcome of these interviews was concretized in the templates associated with each building block. The business entity selected was the collaborative order management because is a critical process for the company. Information systems and information technology are essential to support this process.

The business and IS/IT conceptualization was carried out after identifying business entity. With the definition of the alignment heuristic at this stage was possible to identify aspects that had not been well resolved in the conceptualization. The strategic dependencies model has helped to identify the dependencies between macro-level actors, which have allowed detecting bottlenecks and vulnerabilities. The business processes and IS / IT definition phase started when the conceptualization phase was concluded. Among other benefits, the application and services portfolio has enabled linking the enterprise business processes to applications and services at the macro level through goals. Also, this has allowed a prioritization of the applications. The maturity model has allowed a detailed analysis of the alignment between business and IS / IT, with an allocation of values from one to five, where one represents the lowest value. For the company, the result was less than two, which represents an emerging alignment. This encouraged the company to improve some aspects. An example of a template (the Portfolio application template) is shown below (Fig 4).

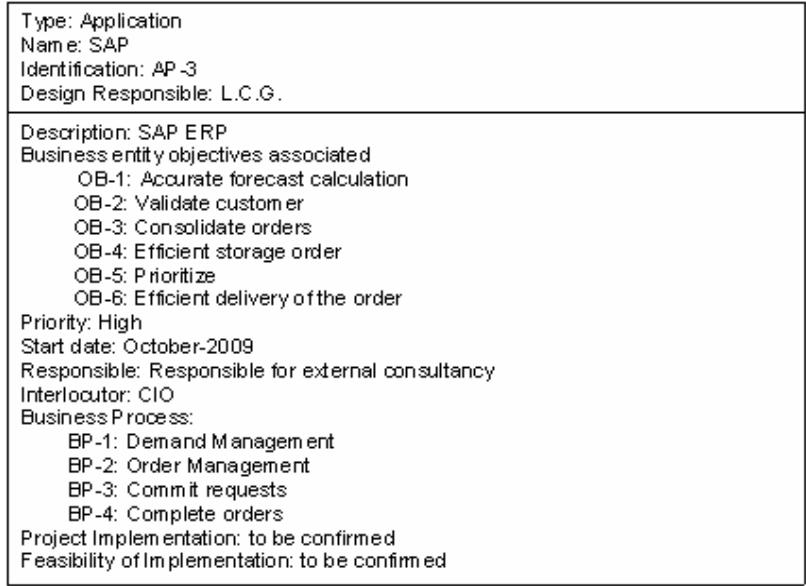

Fig. 4. Portfolio application template

\section{Conclusions and Future Lines}

This paper puts forward the needs for a consistent and integrated modeling framework to incorporate the information, resources, data, and technological views in the early life cycle phase to facilitate strategic alignment. The analysis of strategic alignment 
models has allowed to identify the elements needed for strategic planning of IS/IT and its alignment with the business strategy. These elements have been defined by building blocks and incorporated into CIMOSA and IE-GIP modeling frameworks.

This research presents a significant contribution to enterprise architecture field. The application to a ceramic tile company has helped to validate the usefulness of the proposed modeling framework. This research is part of ongoing research in enterprise engineering field. Future lines of work are raised by the definition of ontology for the proposed modeling framework. A second line of work is proposed to integrate this proposal with the performance measurement architecture and its associated information system, ensuring alignment with business strategy. Finally life cycle phases can be extended to those aspects based on a cyclical methodology for business reengineering.

\section{References}

1. Chen, D., Doumeningts, G., Vernadat, F.: Architectures for enterprise integration and interoperability: past, present and future. Computers in industry 59, 647-659 (2008)

2. Henderson, J.C., Venkatraman, N.: Strategic alignment: Leveraging information technology for transforming organizations. IBM systems journal 32(1), 472-484 (1993)

3. Hirschheim, R., Sabherwal, R.: Detours in the Path toward Strategic Information Systems Alignment. California Management Review, Fall 44(1), 87-108 (2001)

4. Sabherwal, R., Chan, Y.: Alignment between Business and IS Strategies. Information Systems Research 12(1), 11-33 (2001)

5. Peppard, J., Breu, K.: Beyond Alignment: A coevolutionary view of the information systems strategy process. In: Twenty-fourth International Conference on Information Systems (2003)

6. Ciborra, C.U.: De profundis? Deconstructing the concept of strategic alignment. Scandinavian journal of Information Systems 9(1), 67-82 (1997)

7. Scott, G.M.: Still not solved: the persistent problem of IT strategic planning. Communications of the Association for Information Systems 16, 904-936 (2005)

8. Silvius, G.A.J.: Business and IT alignment in theory and practice. In: Proceedings of the 40th Hawaii International Conference on Systems Sciences, Hawaii (2007)

9. King, W.R.: Strategic Planning for Management Information Systems. MIS quarterly 2(1), 27 (1978)

10. Papp, R.: Business-IT alignment:productivity paradox payoff? Industrial Management \& Data Systems 99(8), 367-373 (1999)

11. Bleistein, S.J., Cox, K., Verner, J., Phalp, K.T.: B-SCP: A requirements analysis framework for validating strategic alignment of organizational IT based on strategy, context, and process. Information and Software Technology 48, 846-868 (2006)

12. Vernadat, F.: Enterprise Modeling and Integration. In: Principles and applications. Chapman \& Hall, Boca Raton (1996)

13. Berio, G., Vernadat, F.: Enterprise modelling with CIMOSA: Functional and organizational aspects. Production Planning Control 12(2), 128 (2001)

14. Zachman, J.A.: Concepts of the framework for enterprise architecture. Zachman International Inc.,

http://members.ozemail.com.au/ visible/papers/zachman3.htm

15. Zachman, J.A.: Enterprise architecture - a framework, http://www. zi fa.com

16. TOGAF The Open Group Architecture Framework,

http: / / www . opengroup.org/togaf/ 
17. Spewak, S.: Enterprise Architecture Planning: Developing a Blueprint for Data, Applications, and Technology. Wiley, Chichester (1993)

18. DoD Architecture Framework. Version 1.5. Volume I: Definitions and Guidelines,. DoD Architecture framework Version 1.5., http: / / www. defenselink.mil/cio-nii/docs

19. CIMOSA: Open System Architecture for CIM. 2nd extended revised version. Springer, Berlin (1993)

20. IFIP-IFAC Task Force, GERAM: Generalized Enterprise Reference Architecture and Methodology, Version 1.6.2, Annex to ISO WD15704, IFIP-IFAC Task Force (1999)

21. Ortiz, A., Lario, F., Ros, L.: IE-GIP. A proposal for a Methodology to Develop Enterprise Integration Program. Computers in Industry 40, 155-171 (1999)

22. Luftman, J.: Assessing business-it alignment maturity. Communications of the association for information systems 4(14) (2000)

23. Maes, R.: A Generic Framework for Information Management. Prime Vera Working Paper, Universiteit Van Amsterdam (1999)

24. Santana, R.G., Daneva, M., van Eck, P.A.T., Wieringa, R.J.: Towards a business-IT alignment maturity model for collaborative networked organizations. In: Proceedings of the International Workshop on Enterprise Interoperability Munich, Germany, pp. 70-81 (2008)

25. Wilton, D.: The Relationship Between IS Strategic Planning and Enterprise Architectural Practice, pp. 100-107 (2004)

26. Wegmann, A., Balabko, P., Le, L., Reveg, G., Rychkova, I.: A Method and Tool for Business-IT Alignment. In: Enterprise Architecture Proceedings of the caise, Porto Univ., Porto, Portugal (2005)

27. Pereira, C., Sousa, P.: Enterprise Architecture: Business and IT Alignment. In: ACM Symposium on Applied Computing (2005)

28. Lindström, A.: An Approach for Developing Enterprise-Specific ICT Management Methods - from Architectural Principles to Measures (2006)

29. Versteeg, G., Bouwman, H.: Business architecture: A new paradigm to relate business strategy to ICT. Inf. Syst. Front 8, 91-102 (2006)

30. Plazaola, L., Flores, J., Silva, E., Vargas, N., Ekstedt, M.: An Approach to Associate Strategic Business-IT Alignment Assessment to Enterprise Architecture. In: Conference on Systems Engineering Research, Stevens Institute of Technology Campus, USA (2007)

31. Gammelgård, M., Simonsson, M., Lindström, A.: An IT management assessment framework: evaluating enterprise architecture scenarios. Inf. Syst. E-Business Management 5(4), 415-435 (2007)

32. Wang, X., Zhou, X., Jiang, L.: A method of business and IT alignment based on enterprise architecture (2008)

33. Martin, R., Robertson, E.: Frameworks: comparison and correspondence for three archetypes (2002)

34. EN/ISO 19439 Enterprise integration — Framework for enterprise modeling (2006)

35. EN/ISO 19440 Enterprise integration — Constructor for enterprise modeling (2007)

36. Cuenca Ll., Ortiz A., Boza, A.: Marco arquitectónico para la propuesta IE-GIP. Extensión de la Arquitectura CIMOSA. Aplicación a una empresa del sector cerámico. Universidad Politécnica de Valencia. PhD thesis (2009)

37. Yu, E.: Modeling Strategic Relationships for Process Reengineering. PhD thesis (1995) 